\title{
BRCA role changes with association: tissue-specific impact on the prognosis
}

\author{
Bhavana Gupta ${ }^{1}$ and Kumaravel Somasundaram ${ }^{1}$ \\ ${ }^{1}$ Department of Microbiology and Cell Biology, Indian Institute of Science, Bangalore-560012, India \\ Correspondence to: Kumaravel Somasundaram, email: skumarl@iisc.ac.in
}

Commentary on: Leaf et al. Opposing effects of BRCA 1 mRNA expression on patient survival in breast and colorectal cancer and variation among African American, Asian, and younger patients. Oncotarget. 2021; 12:1992-2005. https://doi.org/10.18632/ oncotarget.28082. [PubMed]

Keywords: BRCA1; prognosis; tissue-specificity

Received: November 15,2021 Accepted: December 01,2021 Published: December 21, 2021

Copyright: @ 2021 Gupta and Somasundaram. This is an open access article distributed under the terms of the Creative Commons Attribution License (CC BY 3.0), which permits unrestricted use, distribution, and reproduction in any medium, provided the original author and source are credited.

The tumor suppressor BRCA (BReast $C A$ ncer) genes are majorly involved in biological processes such as DNA damage response, gene transcription regulation, cell cycle, and apoptosis. It was identified in the early 90 s that germ line mutations in BRCA1 increase the risk of breast and ovarian cancer [1]. Subsequently, several studies in breast cancer patients found an association of BRCA1 expression levels and mutation status with the patient survival. BRCA genes correlated with favorable overall survival (OS) in some cancers, while opposing effects have also been reported [2]. There are several speculations about this tissue-specificity of BRCA1 gene, but only a few attempts have been made to analyze these theories systematically or experimentally.

The recently published study in Oncotarget [3] contributes to the idea of the tissue-specific impact of BRCA1 expression level on the prognosis of the patient. For this objective, they chose breast cancer (BC) and colorectal cancer (CRC) since there is prior work reporting the conflicting prognostic significance of BRCA1 in these cancers. Authors have stated that "BRCA1 mRNA-low tumor expression positively correlated with $\mathrm{BC}$ patient survival but was negatively associated in CRC". These tissue type-specific associations are explained by the correlation of BRCA1 mRNA expression with different genes in these cancers. In conclusion, the authors show that BRCA1 level correlates with TOP2A and ATAD5 both in $\mathrm{BC}$ and $\mathrm{CRC}$ and uniquely with LMNB2 in CRC [3].

Our analysis also observed opposing effects of BRCA genes on patient survival outcomes in different cancers. Similar to Leaf et al., 2021, BRCA1 levels correlated with the poor and good prognosis in $\mathrm{BC}$ and $\mathrm{CRC}$, respectively $[4,5]$. Mei et al., 2020 independently analyzed the prognostic value of BRCA1 using the Kaplan-Meier plotter database in pan-cancer data. In only 5 out of 19 cancers, BRCA1 expression correlated with
OS, where two cancers were associated with favorable OS and the remaining three with worse OS supporting the idea of Leaf et al., 2021 [6].

BRCA1 germ line mutations result in altered expression and are reported to affect overall survival. Similar to BRCA1 gene expression, mutants also exhibit tissue-specificity [7]. A study by Zhu et al., 2016 demonstrated that mutation carriers in breast cancer had a poor prognosis compared to Feng et al., 2020 study in CRC, where carriers had favorable responses to chemotherapy $[8,9]$. In line with the earlier studies, patients with BRCA1 mutant had poor OS in BC but better OS in CRC.

The idea of tissue-specific opposing effects of BRCA genes on prognosis could be because of their differential interactions with either tumor-suppressor or oncogenes, ultimately affecting the BRCA pathway functional ability. Given the background of BRCA complex behavior and its various biological functions, BRCA1 therapeutic effects may depend on the specificity of the tissue, genetic background, and its multiple mechanisms of action. Further investigation on BRCA interacting spectrum will hopefully elucidate the underlying mechanisms in detail and ultimately help in the advancement of medical interventions.

\section{ACKNOWLEDGMENTS}

BG acknowledge DST-INSPIRE for the research fellowship. KS acknowledges CSIR, DST, ICMR, SERB, CEFIPRA, and DBT, Government of India, for research grants. Infrastructure support by funding from DST-FIST and UGC (Center for Advanced Studies in Molecular Microbiology) to MCB and DBT-IISc partnership program is acknowledged. KS is a J. C. Bose Fellow of the Department of Science and Technology. 


\section{REFERENCES}

1. Varol U, Kucukzeybek Y, Alacacioglu A, Somali I, Altun Z, Aktas S, Oktay Tarhan M. BRCA genes: BRCA 1 and BRCA 2. J BUON. 2018; 23:862-66. [PubMed]

2. Lee YC, Lee YL, Li CY. BRCA Genes and Related Cancers: A Meta-Analysis from Epidemiological Cohort Studies. Medicina (Kaunas). 2021; 57:905. https://doi.org/10.3390/ medicina57090905. [PubMed]

3. Leaf S, Carlsen L, El-Deiry WS. Opposing effects of BRCA1 mRNA expression on patient survival in breast and colorectal cancer and variations among African American, Asian, and younger patients. Oncotarget. 2021; 12:19922005. https://doi.org/10.18632/oncotarget.28082. [PubMed]

4. Wang Z, Zhang J, Zhang Y, Deng Q, Liang H. Expression and mutations of BRCA in breast cancer and ovarian cancer: Evidence from bioinformatics analyses. Int J Mol Med. 2018; 42:3542-50. https://doi.org/10.3892/ijmm.2018.3870. [PubMed]

5. Yuanming L, Lineng Z, Baorong S, Junjie P, Sanjun C. BRCA1 and ERCC1 mRNA levels are associated with lymph node metastasis in Chinese patients with colorectal cancer. BMC Cancer. 2013; 13:103. https://doi. org/10.1186/1471-2407-13-103. [PubMed]
6. Mei J, Wang R, Xia D, Yang X, Zhou W, Wang H, Liu C. BRCA1 Is a Novel Prognostic Indicator and Associates with Immune Cell Infiltration in Hepatocellular Carcinoma. DNA Cell Biol. 2020; 39:1838-49. https://doi.org/10.1089/ dna.2020.5644. [PubMed]

7. Semmler L, Reiter-Brennan C, Klein A. BRCA1 and Breast Cancer: a Review of the Underlying Mechanisms Resulting in the Tissue-Specific Tumorigenesis in Mutation Carriers. J Breast Cancer. 2019; 22:1-14. https://doi.org/10.4048/ jbc.2019.22.e6. [PubMed]

8. Zhu Y, Wu J, Zhang C, Sun S, Zhang J, Liu W, Huang J, Zhang Z. BRCA mutations and survival in breast cancer: an updated systematic review and meta-analysis. Oncotarget. 2016; 7:70113-27. https://doi.org/10.18632/ oncotarget.12158. [PubMed]

9. Feng S, Al-Showbaki L, Krzyzanowska MK, Prince MR, Stockley T, Yu C, Bedard P, Siu LL, Chen EX. BRCA mutations in metastatic colorectal cancer (mCRC) and response to chemotherapy. J Clin Oncol. 2020; 38:235. https://doi.org/10.1200/JCO.2020.38.4 suppl.235. 